\title{
FEM analysis of a new miniplate: stress distribution on the plate, screws and the
} bone

\author{
Didem Nalbantgil ${ }^{1}$ \\ Murat Tozlu' ${ }^{1}$ \\ Fulya Ozdemir ${ }^{1}$ \\ Mehmet Oguz Oztoprak \\ Tulin Arun²
}

\section{ABSTRACT}

Objectives: Non-homogeneous force distribution along the miniplates and the screws is an unsolved question for skeletal anchorage in orthodontics. To overcome this issue, a miniplate structure was designed featuring spikes placed on the surface facing the cortical bone. The aim of this study was to examine and compare the force distribution of the newly designed plate-screw systems with the conventional one.

Methods: A model of bone surface with $1.5 \mathrm{~mm}$ cortical thickness, along with the two newly designed miniplates and a standard miniplate-screw were simulated on the three-dimensional model. $200 \mathrm{~g}$ experimental force was applied to the tip of the miniplates and the consequential effects on the screws and cortical bone was evaluated using three-dimensional finite element method.

Results: As a result of this finite element study, remarkably lower stresses were observed on the screws and the cortical bone around the screws with the newly designed miniplate when compared with the conventional one.

Conclusion: The newly designed miniplate that has spikes was found effective in reducing the stress on and around the screws and the force was distributed more equivalently. (Eur J Dent 2012;6:9-15)

Key Words: Miniplate, stability, stress distribution, finite element analysis

\section{INTRODUCTION}

Anchorage is one of the major issues for orthodontic treatment success. Missing permanent teeth and non-compliance of the patients can pose anchorage problems during treatment. To elimi-

1 Department of Orthodontics, Faculty of Dentistry, Yeditepe University, Istanbul, TURKIYE.

2 Private practice, Istanbul, TURKIYE.

- Corresponding author: Dr. Murat Tozlu, Department of Orthodontics, Faculty of Dentistry, Yeditepe University, Bagdat Cad. No 238 Goztepe Istanbul, TURKIYE. Tel: +902163636044

Email: tozlumuratagmail.com nate these problems, intraoral skeletal anchorage systems, such as palatal implants ${ }^{1}$, retromolar implants, ${ }^{2}$ onplants, ${ }^{3}$ zygomatic ligatures, ${ }^{4}$ miniscrews $^{5-9}$ and miniplates ${ }^{10,11}$ have been introduced to clinical use.

Currently, miniscrews and miniplates are being widely used because of their small size and superiority over endossous implants due to the fact that they can be immediately loaded. Miniplates basically have the same features with the plates used in maxillofacial surgery. Unlike these miniplates, 
orthodontic miniplate's one end is fixed to the cortical bone and the other end has attachments to engage orthodontic auxiliaries.

Umemori et al, ${ }^{11}$ and Jenner and Fitzpatrick ${ }^{12}$ were the first ones to use maxillofacial bone plates for skeletal anchorage in orthodontics. Since then, mini-plate design variations have been introduced like MPI (Tasarımmed, Istanbul, Turkey), ${ }^{10}$ Bollard Mini Plate(Surgitec, Bruges, Belgium), ${ }^{13}$ Ctube miniplate (KLS Martin, Umkirch, Germany), ${ }^{14}$ and Surgitec Zygoma Anchor Miniplate (Surgitec, Bruges, Belgium). ${ }^{15}$ With the aid of miniplates, intrusion of single or groups of teeth, alignment of severe crowding, correction of severe Class II malocclusion, and management of anterior open bite have been accomplished succesfully. ${ }^{10,11,14,16}$ On the other hand, besides these successful case reports clinical studies regarding miniplates had reported high failure rates of $7-8.6 \%$. Inflammation around the neck and the forces effecting on the stability of the fixation screws are shown to be the reasons for these failures. ${ }^{17,18}$ Veziroglu et al ${ }^{19}$ that, inadequate design and non-homogeneous force distribution along the anchorage system can cause stress directly effecting on the screws and may impair screw stability. They also added that, mobile plates can irritate the surrounding tissues and may be the reason for initiating or aggravating the inflammation around the neck of the miniplate piercing the oral mucosa.

A design that prevents the stress acting nonhomogeneously on the fixation screws can be a solution to avoid mobilization of screws, and consequently inflammation that may arose due to mobilized screws.

With the use of three dimensional finite element method (FEM), load transfer of orthodontic forces from the screws to the bone and the stress distribution around these can be effectively evaluated. ${ }^{17,20,21}$

Thus, the aims of this FEM study were to (1) design a new miniplate structure featuring spikes placed on the surface facing the cortical bone, referred as spiky miniplate, and (2) compare with the use of FEM the force distribution along the conventional miniplate-screw system and the newly designed spiky miniplates inserted to the cortical bone.

\section{MATERIALS AND METHODS}

This study was carried out by Yeditepe University Faculty of Dentistry and Ay Tasarim Ltd.. Nextengine (NextEngine Inc. Santa Monica, California 90401 USAl laser scanner was used for three-dimensional scanning and Rhinoceros 4.0 (3670 Woodland Park Ave.,Seattle, WA 98103 USA) three-dimensional software modeling and Algor Fempro (ALGOR, Inc. 150 Beta Drive Pittsburgh, PA 15238-2932 USAl softwares were used for analysis. All the materials used were predefined as homogeneous and isotropic. Titanium material used in this FEM study was pure titanium. The characteristics (Elasticity modulus and Poisson's ratio) $^{22}$ of the materials are given in Table 1. Cortical bone thickness was assumed as $1.5 \mathrm{~mm}$ in the models. ${ }^{23,24}$ The screws used in the study had a diameter of $2 \mathrm{~mm}$ and a length of $5 \mathrm{~mm}$. The dimensions of the miniplates are given at Figure 1a, b. The interface between the screw and the host bone was assumed to be fully bonded, consistent with screw-material interfaces. The spikes had a length of $0.7 \mathrm{~mm}$ and a base diameter of $0.6 \mathrm{~mm}$ and are assumed to be fully penetrated into the bone. The miniplate and cancellous bone were subtructed from the cortical plate using Boolean method..$^{25}$ This enabled the transfer of force in finite element analysis software. The models were fixed at the lower and lateral surfaces to keep fixation sites away from the experimental region.

Three different experimental designs were used. In all of the designs, $200 \mathrm{~g}$ force was applied at the same point to the miniplate towards the same direction (Figure 1a).

New spiky miniplates and the conventional plate tested in the study were modelled by using Rhinoceros 4.0 software. The three models obtained were as follows (Figure 2):

1. Conventional miniplate design with two screw holes

2. Newly designed miniplate with four spikes with two screw holes

3. Newly designed miniplate with four spikes with single screw hole

\section{RESULTS}

The maximum stress values created on the miniplates and screws are given in Tables 2 and 3 and the data for bone are given in Table 4.

Several terms had been used throughout the 
manuscript for the parts of the screws and spikes according to their localization. For the two-holed miniplates, the term 'near screw' has been used term 'far screw' was used for the distant screw. Similarly, for the spikes the terms 'near spikes' and 'far spikes' had been used.

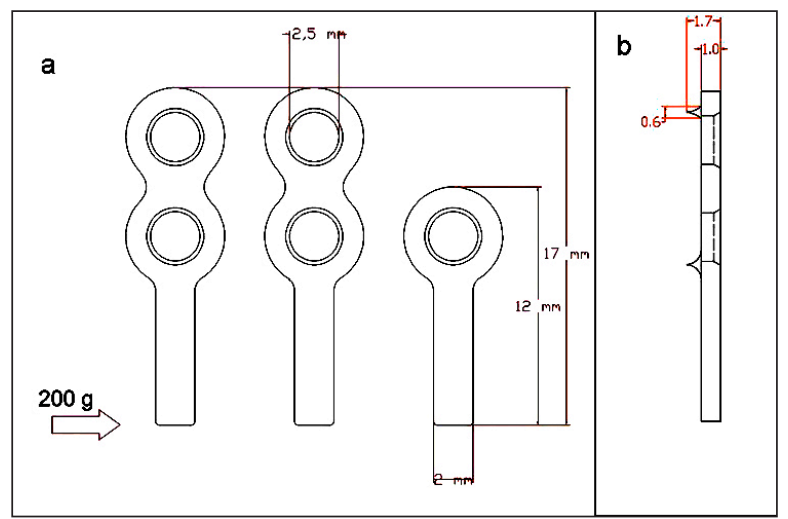

Figure 1. a. Dimensions of the miniplates and the direction of the force applied b, lateral view and dimensions of the two holed spiky miniplate. for the screw that is adjacent to the lever arm. The

\section{MINIPLATE}

In all of the miniplates the most increased level of stresses were seen at the neck of the miniplates and the point where the force was applied (Table 2 , Figure $3 a-c)$. The maximum stress values for one-holed spiky miniplate were located around all of the spikes; whereas for the two-holed spiky

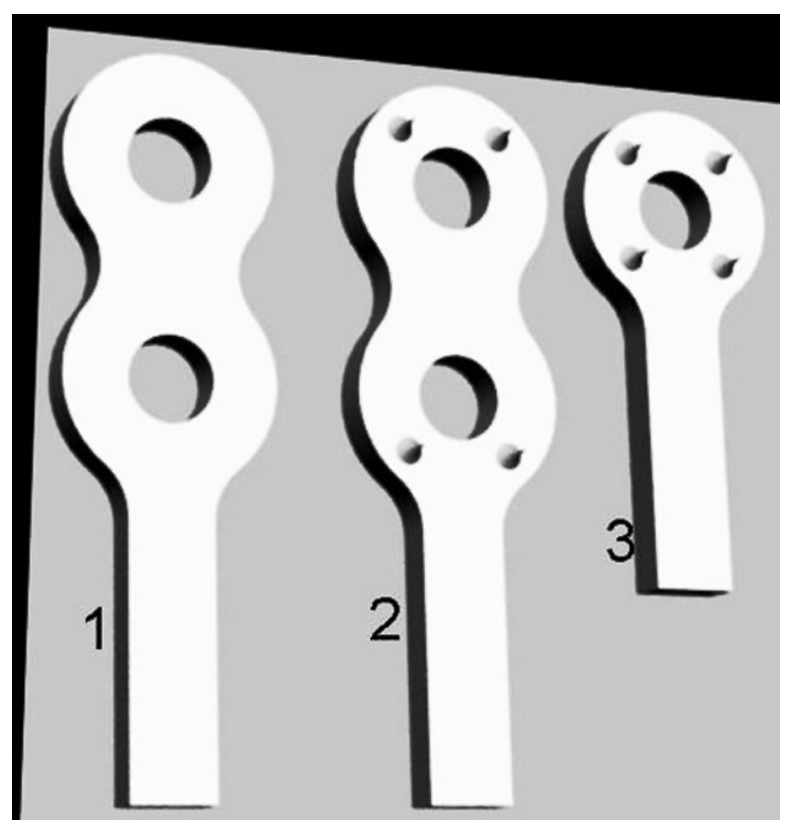

Figure 2. Miniplates used in the study: 1, conventional plate with two screw holes 2, spiky miniplate with two screw holes 3 , spiky miniplate with one screw hole.

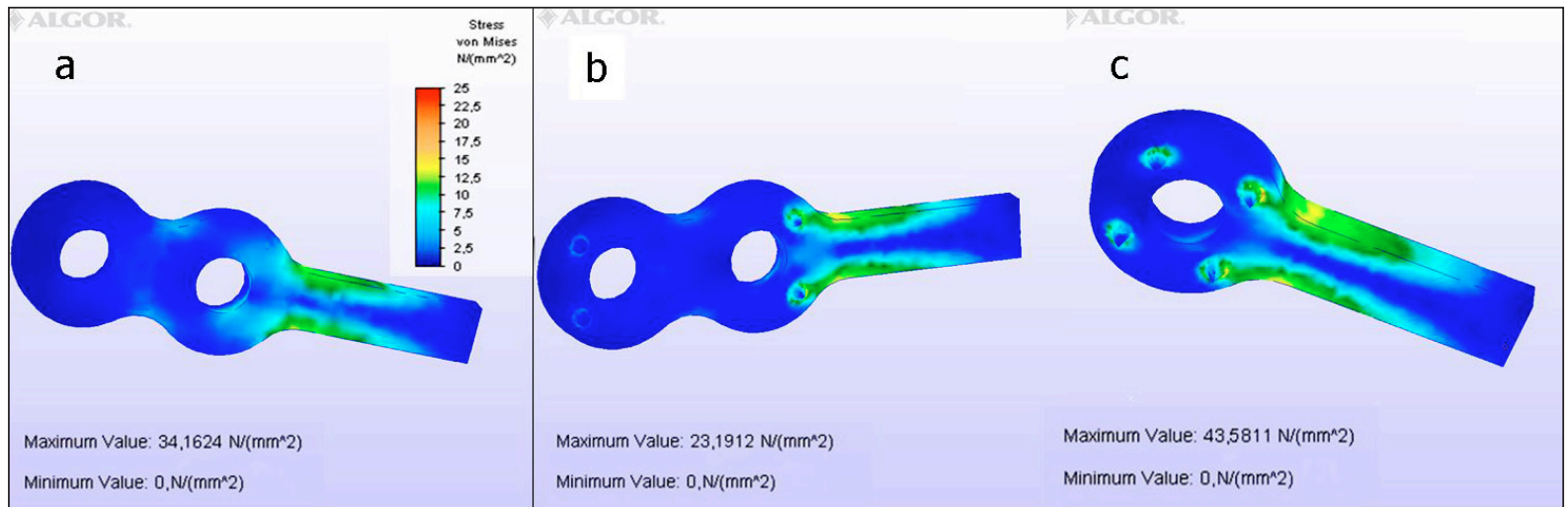

Figure 3. Stress distribution on the miniplates a, conventional miniplate b, two-holed spiky miniplate c, one-holed spiky miniplate.

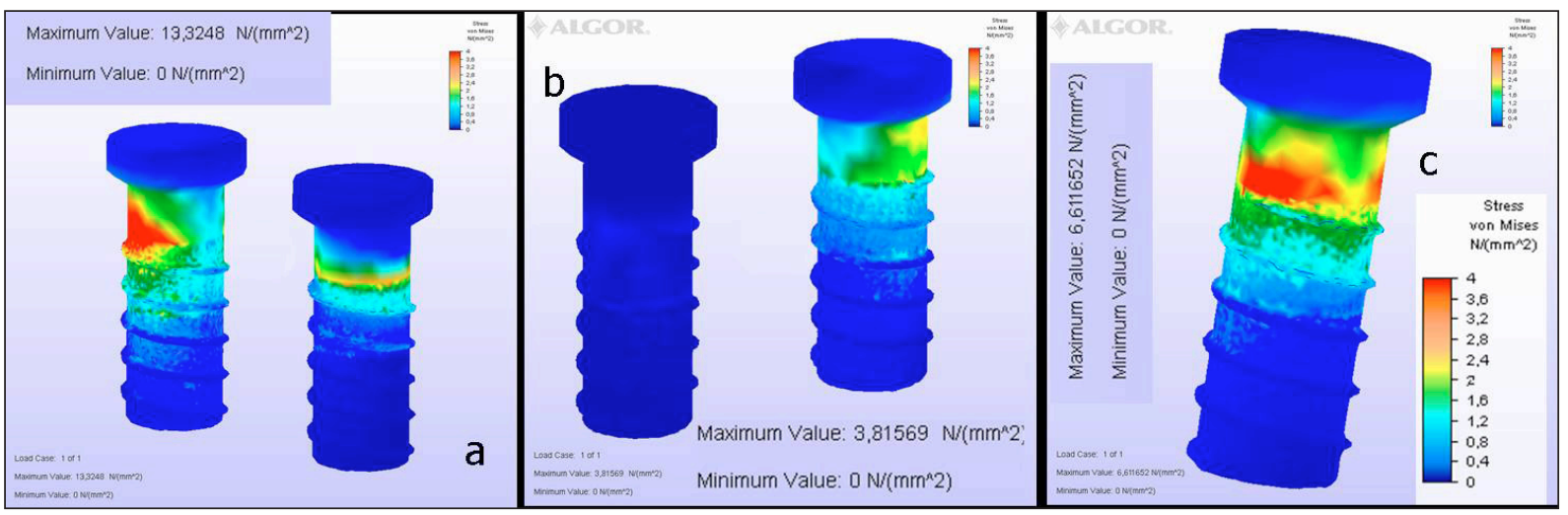

Figure 4. Stress distribution on the screws a, screws of the conventional miniplate b, screws of the two-holed spiky miniplate $\mathbf{c}$, screw of the one-holed spiky miniplate

January 2012 - Vol.6 
miniplate, they were located at the near spikes. The highest stress value recorded for the spikes was $43.58 \mathrm{MPa}$ for the one-holed spiky miniplate. When the highest stress values around the screw holes were evaluated, similar stress values were observed (Table 3).

\section{SCREW}

In all the screws, except the far screw of the two-holed spiky miniplate, the highest stress level was recorded at the neck (Figure 4). The highest stress value was $13.32 \mathrm{MPa}$ at the near screw of the two-holed conventional miniplate (Table 2, Figure 4a). For the two holed spiky miniplate, almost no stress was observed at the far screw (Figure 4b).

\section{CORTICAL BONE}

The data related to the cortical bone that is in contact with the fixation screws are given in Table 4. The maximum stress recorded for the bone was around the near screw in the two-holed conven-

Table 1. Characteristics of the materials utilized

\begin{tabular}{lcc}
\hline Type of the material & Elasticity Modulus & Poisson's Ratio \\
\hline Titanium & 117,000 & 0.34 \\
Spongious bone & 1500 & 0.3 \\
Cortical bone & 15,000 & 0.33 \\
\hline
\end{tabular}

Table 2. Highest stress values in the miniplate and screws.

\begin{tabular}{lc}
\hline Model 1 (Two-holed classical) & Von Mises Stress (MPa) \\
\hline Plate & 34.16 \\
Near Screw & 13.32 \\
Far Screw & 3.91 \\
\hline Model 2 (Two-holed spiky) & 23.19 \\
\hline Plate & 3.81 \\
Near Screw & 0.38 \\
\hline Far Screw & \\
\hline Model 3 (One-holed spiky) & 43.58 \\
\hline Plate & 6.61 \\
\hline Screw & \\
\hline
\end{tabular}

Table 4. Highest stress values in the cortical bone surrounding the screws.

\begin{tabular}{|c|c|c|}
\hline Model 1 (Two-holed classical) & $\begin{array}{l}\text { Maximum Principle } \\
\text { (tension) (MPa) }\end{array}$ & $\begin{array}{l}\text { Minimum Principle } \\
\text { (compression) (MPa) }\end{array}$ \\
\hline Cortical bone around near screw & 1.51 & -1.34 \\
\hline Cortical bone around far screw & 0.46 & -0.40 \\
\hline \multicolumn{3}{|l|}{ Model 2 (Two-holed spiky) } \\
\hline Cortical bone around near screw & 0.65 & -0.80 \\
\hline Cortical bone around far screw & 0.08 & -0.03 \\
\hline \multicolumn{3}{|l|}{ Model 3 (One-holed spiky) } \\
\hline Cortical bone around screw & 0.63 & -0.62 \\
\hline
\end{tabular}

For the two-holed spiky miniplate, the highest stress was found at the region where the near spikes entered the bone (Figure $5 b, 6 b$ ).

For the one-holed spiky miniplate, at the cortical bone level, the highest stress level was found at the region where the spikes entered the bone (Figure 5c, 6c).

The maximum tension and compression stresses seen at the cortical bone around the near screw at the two-holed conventional miniplate were 1.51 and -1.34 MPa, respectively (Table 4).

\section{DISCUSSION}

In the present study, two newly designed miniplates were tested with three-dimensional FEM. The biologic changes due to osseous loading could not be examined within this study. However, threedimensional FEM studies provide the following advantages for the researchers working orthodontic force systems. ${ }^{19}$

1- Simulate oral structures in vitro

2- Simulate the orthodontic force system applied clinically

3- Analyze the response of the bone and the materials used

4- Several experimental designs can be simulated for numerous times keeping the properties of the materials unchanged

5- Newly designed appliances can be tested invitro and non-invasively before clinical use

Table 3. Highest stress values on the miniplates around the screw holes.

\begin{tabular}{lc}
\hline Model 1 (Two-holed classical) & Von Mises Stress (MPa) \\
\hline Near Hole & 3.02 \\
Far Hole & 1.01 \\
\hline Model 2 (Two-holed spiky) & \\
\hline Near Hole & 2.88 \\
Far Hole & 1.55 \\
\hline Model 3 (One-holed spiky) & \\
\hline Hole & 2.62 \\
\hline
\end{tabular}


The three-dimensional FEM was preferred because of the advantages described above prior to clinical application. $200 \mathrm{~g}$ force that is usually used in clinical practice was applied to the miniplates. ${ }^{26}$
As a control, a conventional miniplate that is routinely used in practice was chosen. The data for the new miniplates were compared with those of the conventional one.

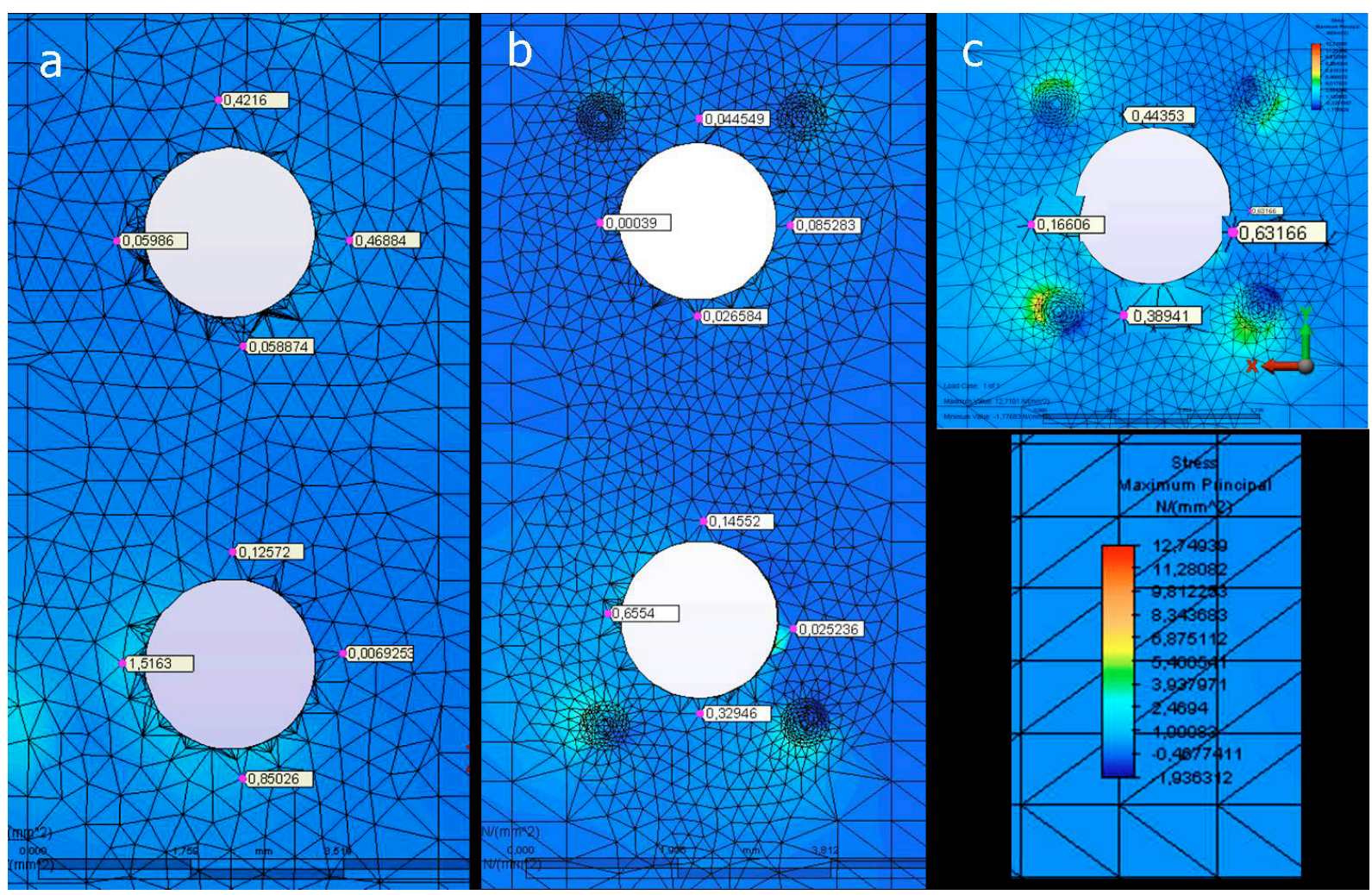

Figure 5. Maximum principlettension) stress distribution on the cortical bone with a, conventional miniplate b, two-holed spiky miniplate $c$, one-holed spiky miniplate.
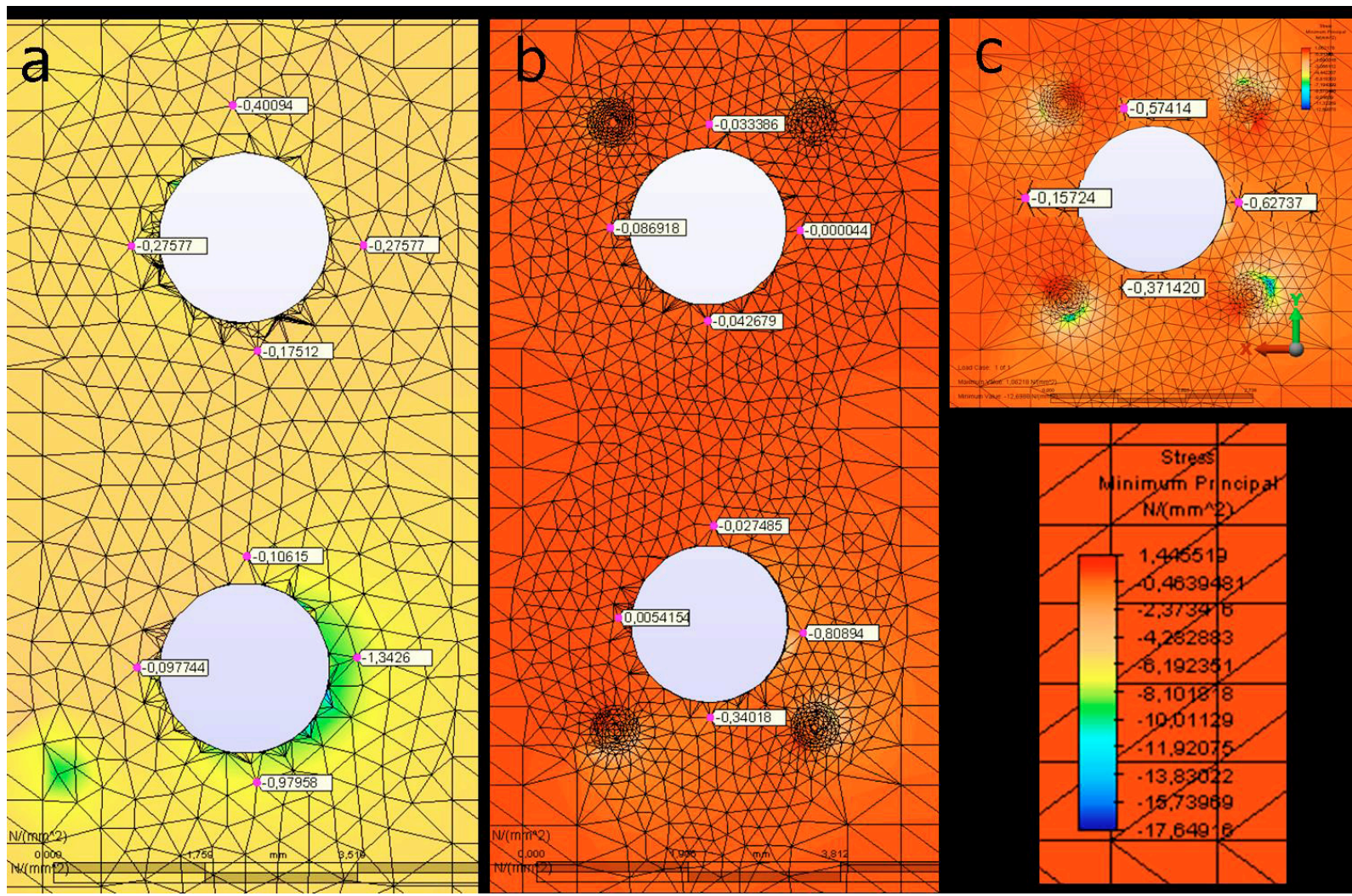

Figure 6. Minimum principle(compression) stress distribution on the cortical bone with a, conventional miniplate b, two-holed spiky miniplate $\mathbf{c}$, one-holed spiky miniplate.

$\square \quad$ January $2012-$ Vol.6 
The results of this study revealed remarkable difference in the stress distribution at the cortical bone that is in contact with the fixation screws between the conventional and the newly designed miniplates. Also the fixation screws received almost half of the stress values for the new miniplates. These results support that biomechanical properties of the miniplates were remarkably improved.

When the two-holed spiky miniplate and twoholed conventional miniplate were compared, the highest tension and compression stress found at the cortical bone around the near screw at the new spiky miniplate was almost half of the conventional one (Table 4). As for the far screw of the spiky miniplate, there was almost no stress at the cortical bone. Similarly the stress level at the body of the screws also showed substantial decrease when spiky miniplate was used which had almost no stress at the far screw (Figure 4b). Comparison of the one- and two-holed spiky miniplates revealed the same amount of tension and compression stresses of 0.63 and $0.65 \mathrm{MPa}$ and -0.62 and -0.80 MPa, respectively (Table 4).

When the one-holed spiky miniplate and twoholed conventional miniplate was compared, even though one-holed spiky miniplate had only one screw, the maximum stress around the screw was half of the conventional one (Table 4). When the data for the screw material was compared, the single screw at the one-holed spiky miniplate was found to carry half of the stress of the near screw in the two holed conventional miniplate had (Table 2, Figure 4).

The failures of miniplates can generally be attributed to two major reasons; stress directly affecting the screws and inflammation. ${ }^{17,18}$ Stability of the miniplates is directly affected by the stability of the fixation screws. Applied forces to the miniplates are transmitted to the screws which create stresses especially on the near screw that may impair the screw stability. ${ }^{19}$ With the conventional plates, load of the orthodontic forces are directly transferred from the plate to screws, whereas with the new ones, spikes act as an barrier before the load reaches the screws.

Non-homogenous stress distribution on the fixation screws is not the only reason for the failures. The reason for the screw loosening is not clear, but Choi et al ${ }^{17}$ reported that it might also be due to insertion technique, force level, force duration, patient's oral hygiene or thickness of cortical bones.

Haug et $\mathrm{al}^{27}$ reported that the stability of the miniplates can be improved by increasing the number of the fixation screws. However, with respect to failure rates, no significant statistical difference was found between the plates with different number of screws. ${ }^{17}$ As a result of the present FEM study, remarkably lower stresses on the fixation screws between the conventional miniplates and the new ones have been observed. These results should also be evaluated regarding failure rates. Also, in time, resorption can occur at the bone around the spikes, and the stresses around the screws may increase. In vivo studies are necessary to investigate possible histological changes to ensure the safety and the stability of the newly designed miniplates.

Cortical bone thickness is one of the major factors for the success rates of the miniscrews. In this study, an average of $1,5 \mathrm{~mm}$ cortical bone thickness was modeled. ${ }^{21,22}$ When the average thicknesses for the cortical bone was considered, a length of $0.7 \mathrm{~mm}$ for the spikes was estimated to be safe in order not to protrude from the cortical bone. If the cortical bone thickness is thin like in vertical-growing patients, then the success rates of miniscrews may be lower than for the average or horizontal-growing patients. ${ }^{28}$ In the light of this knowledge it becomes obvious that maximum support from the cortical bone should be obtained. Spikes on the newly designed miniplates decrease the stress on the screws providing more homogeneous support from the cortical bone.

The major disadvantage of the miniplates is that they must be placed surgically. The advantage of one holed new miniplate is that it can be used with a smaller incision. If there is enough keratinized gingival height, one holed miniplate can be applied with the use of a punch to excise the soft tissue. Thus, the miniplate can be applied with very small surgery with no incision or sutures.

\section{CONCLUSION}

This study reported the newly designed miniplates featuring spikes placed on the surface facing the cortical bone. The FEM study revealed that the new miniplates are highly efficient in reducing stress on the fixation screws. Clinical studies on 
the failure rates of new miniplates should be carried out.

\section{REFERENCES}

1. Wehrbein H, Merz BR, Diedrich P, Glatzmaier J. The use of palatal implants for orthodontic anchorage. Design and clinical application of the orthosystem. Clin Oral Implants Res 1996;7:410-416.

2. Roberts WE, Helm FR, Marshal KJ, Gongloff RK. Rigid endosseous implants for orthodontic and orthopaedic anchorage. Angle Orthod 1989;59:247-256.

3. Block MS, Hoffman DR. A new device for absolute anchorage for orthodontics. Am J Orthod Dentofacial Orthop 1995;107:251-258.

4. Melsen B, Petersen JK, Costa A. Zygoma ligatures: an alternative form of maxillary anchorage. J Clin Orthod 1998;32:154-158.

5. Kanomi R. Mini-implant for orthodontic anchorage. J Clin Orthod 1997;31:763-767.

6. Costa A, Raffaini M, Melsen B. Microscrews as orthodontic anchorage: a preliminary report. Int J Adult Orthod Orthognathic Surg 1998;13:201-209.

7. Lee JS, Park HS, Kyung HM. Micro-implant anchorage for lingual treatment of a skeletal class II malocclusion. J Clin Orthod 2001;35:643-647.

8. Park HS, Bae SM, Kyung HM, Sung JH. Micro-implant anchorage for treatment of skeletal Class I bialveolar protrusion. J Clin Orthod 2001;35:417-422.

9. Polat-Ozsoy 0. The use of intraosseous screw for upper molar distalization: a case report Eur J Dent 2008;2:115121.

10. Erverdi N, Usumez S, Solak A. New generation openbite treatment with zygomatic anchorage. Angle Orthod 2006;76:519-526.

11. Umemori M, Sugawara J, Mitani H, Nagasaka H, Kawamura H. Skeletal anchorage system for open-bite correction. Am J Orthod Dentofacial Orthop 1999;115:166-174.

12. Jenner JD, Fitzpatrick BN. Skeletal anchorage utilizing bone plates. Aust Orthod J 1985;9:231-233.

13. Cornelis M, Scheffler N, Mahy P, Siciliano S, Clerk H, Tulloch C. Modified miniplates for skeletal anchorage in orthodontics:placement and removal surgeries. $J$ Oral Maxillofacial Surg 2008;66:1439-1445.

14. Chung K, Kim Y, Linto JL, Lee Y. The miniplate with tube for skeletal anchorage. J Clin Orthod 2002;36:407-412.

15. De Clerk H, Geerinckx V, Sciliano S. The zygoma anchorage system. J Clin Orthod 2002;36:455-459.

16. Sherwood KH, Burch J, Thompson W. Intrusion of supererupted molars with titanium miniplate anchorage. Angle Orthod 2003;73:597-601.
17. Choi BH, Zhu JS, Kim HY. A clinical evaluation of titanium miniplates as anchors for orthodontic treatment. Am J Orthod Dentofacial Orthop 2005;128:382-384.

18. Mommaerts MY, Michiels E, De Pauw G. A 2-year outcome audit of a versatile orthodontic bone anchor. J Orthod 2005;32:175-181.

19. Veziroglu F, Uckan S, Ozden UA, Arman. A Stability of Zygomatic Plate-Screw Orthodontic Anchorage System. Angle Orthod 2008;78:902-907.

20. Gracco A, Boccaccio A, Cirignaco A, Cozzani M, Pappalettere C, Vitale G. Numerical/experimental analysis of the stress field around miniscrews for the orthodontic anchorage. Eur J Orthod 2009 Feb;31:12-20.

21. Dalstra M, Cattaneo P, Melsen B. Load transfer of miniscrews for orthodontic anchorage. Orthod 2004;1: 53-62.

22. Nagasao T, Kobayashi M, Tsuchiya Y, Kaneko T, Nakajima T. Finite element analysis of the stresses around endosseous implants in various reconstructed mandibular models. J Craniomaxillofac Surg 2002;30:170-177.

23. Park J, Cho H. Three-dimensional evaluation of interradicular spaces and cortical bone thickness for the placement and initial stability of microimplants in adults. Am J Orthod Dentofac Orthop 2009;136:314-315.

24. Baumgaertel S,Hans M. Buccal cortical bone thickness for mini-implant placement. Am J Orthod Dentofacial Orthop 2009; 136:230-235.

25. Li W, Swain MV, Li Q. Towards automated 3D finite element modeling of direct fiber reinforced composite dental bridge. J Biomed Mater Res B Appl Biomater 2005;74:520528.

26. Reynders R, Ronchi L, Bipat S. Mini-implants in orthodontics: A systematic review of the literature. Am J Orthod Dentofac Orthop 2009;135:564.e1-564.e19.

27. Haug R. The effect of screw number length on two methods of tension and plating. J Oral Maxillofac Surg 1993;51:159162.

28. Miyawaki S, Koyama I, Inoue M, Mishima K, Sugahara T, Takano-Yamamoto T. Factors associated with the stability of titanium screws placed in the posterior region for orthodontic anchorage. Am J Orthod Dentofacial Orthop 2003; 124:373-378. 